\title{
The Journal of Plant Pathology Editors' Choice August 2021
}

\author{
Published online: 5 August 2021 \\ (c) Società Italiana di Patologia Vegetale (S.I.Pa.V.) 2021
}

The August issue of the Journal of Plant Pathology showcases four Editors' Choice (EC) papers, selected from a shortlist of 10 excellent studies. Two of the four finalist papers provide insights on how to achieve a "greener" and safer agriculture by deploying new biocontrol strategies or breeding crop varieties for resistance. A third paper describes the local insurgence of new and genetically welldefined pathogenic strains, a topic of great relevance for the understanding of the epidemiology of plant diseases, one that is conceptually not very dissimilar from the local insurgence of novel variants of the Covid-19 virus. Finally, the fourth Editors' Choice paper studies the genetic mechanisms of disease resistance and how such mechanisms may be impacted by increasing temperatures: in light of global warming trends, this last study is also particularly interesting and timely. The common thread across the four EC papers is the focus on local crop varieties and pathogens' strains. We believe that a focus of native germplasm, locally grown crop lines and also on locally dominant pathogen genotypes or strains may not only be welcomed but much needed in a scientific arena often dominated by the use of "model systems". While we acknowledge the huge progress made thanks to the use of model systems, we also strongly believe it is pivotal we foster research that transcends model pathosystems, while placing the emphasis on locally relevant issues, so that traditional crops and traditional growing practices may be maintained and improved rather than being substituted by commercially available crops and industrial agricultural practices.

In "Pseudomonas oryzihabitans: a potential bacterial antagonist for the management of bacterial fruit blotch (Acidovorax citrulli) of cucurbits", Sumer Horuz (Turkey) describes the valuable pathogen antagonistic activity ( $>50 \%$ disease incidence reduction and $70 \%$ disease severity reduction) and yield increasing effect ( $>40 \%$ increase) of seed and plant treatments under greenhouse conditions of watermelon infected by the bacterial fruit blotch pathogen Acidovorax citrulli, when co-inoculated with the soil/rhizosphere bacterium Pseudomonas oryzihabitans. It should be noted that while $P$. oryzihabitans has been reported as an opportunistic pathogen of humans and as a pathogen of muskmelon and rice, some strains of this organism, as shown by this paper, appear to be beneficial on fruit trees, cotton and potato. This study highlights the importance of avoiding general categorization of organisms and of performing detailed population studies using local populations. It also underlines the importance of pairing genotypic and phenotypic analyses. The author will continue research under field conditions of this interesting and promising antagonist of a worldwide very important bacterial pathogen of (water)melon. We look forward to their future research results.

In "Population Structure of Phytophthora infestans (Mont.) de Bary in Ethiopia", Esmelealem Mihretu and co-authors (Ethiopia and Peru) investigated the population structure and the population genetics of the oomycete Phytophthora infestans in the major potato production areas of Ethiopia. The genotypic patterns deriving from SSR and mitochondrial haplotype analyses were compared to those of reference isolates from the EU2_A1 and US-1 clonal lineages, which are globally dominant. The authors were able to demonstrate that while most $P$. infestans isolates from Ethiopia were similar to the EU2_A1 the remaining isolates could not be assigned to EU2_A1 or US-1 and thus represented a new lineage the authors defined as ET-1. US-1 was notably absent, suggesting it has been replaced by other genotypes, presumably characterized by higher fitness. Three Ethiopian regions displayed a higher genotypic diversity, and in one of these regions, the locally evolved ET-1 genotype was dominant. This finding is obviously of great local relevance, but it also further highlights the strong correlation between high genetic diversity of pathogen populations and the insurgence of novel dominant genotypes, which may later attain local, regional or global relevance. This study, resulting from a cooperation of local universities and research centres of Peru, provides insights into the population diversity and distribution of lineages of a major pathogen in a relatively poorly studied world region.

In "Inheritance of resistance in chilli against root and collar rot caused by Phytophthora capsici", Manish Kumar and co-authors (India) tackle a serious issue for local growers of commercial chilli (Capsicum annиum L.) who repeatedly 
and necessarily grow the crop in the same soil under canal gravity irrigation rather than using drip irrigation. Given that these traditional growing practices are particularly conducive to infection by Phytophthora disease and given that crop rotation and solarization are not feasible, chemical control and the use of resistant crop varieties are the only possible alternatives. In this study, the authors pursue the development of resistance by providing information on the mechanism conferring resistance to Phytophthora capsici using multiple commercial and locally grown chilli genotypes and a locally dominant and virulent genotype of the pathogen, making this study particularly relevant to local growers. The study not only identifies a chilli genotype highly resistant to the locally dominant pathogen strain, but also uncovers that resistance is conferred by a major dominant gene and by some additional minor genes. As the authors state: "the confirmation of resistance against virulent local isolate may allow the search of new resistant genes for other isolates which would be utilised for pyramiding of the multiple resistant genes into locally adapted materials to impart resistance to different isolates of $P$. capsic $i$ in chilli. Finally, understanding the genetics of Phytophthora root rot resistance in C. annuиm against local virulent isolates, will help to develop new breeding approaches for effective and durable genetic resistance in commercial chillies."

In "Differential response of Brn1 at varied thermal regimes and its relation with virulence and extracellular release of cellulase and amylase in Alternaria brassicicola ", Sinha et al. (India) use an array of local isolates of this pathogen to comprehensively investigate the effect of temperature on the expression of genes involved in melanin biosynthesis in the dark spored fungus Alternaria brassicicola, the causal agent of black spot of mustard, and its association with the biology of the pathogen, its virulence, and the release of extracellular enzymes such as cellulose and amylase. By combining in an elegant way gene expression analyses, microscopic observations and phenotypic experiments, including pathogenicity tests, the authors were able to measure an increased virulence of A. brassicicola at higher temperatures and provided evidence supporting an involvement of an enhanced release of extracellular enzymes in conjunction with reduced melanin production. Results provided in this paper were in part unexpected and improve our understanding of the pathogenesis of A. brassicicola. Given that over the past decades these crops have become one of the most important sources of vegetable oil in the world and in light of global rising temperatures, the research questions asked by the study are extremely timely. This and other papers document an increase in disease severity at warmer temperatures: the detrimental effects caused by $A$. brassicola may even get intensified by virtue of the pathogen's wide host range, including several economically important vegetable brassicas.

We invite you to pay special attention to the four Editors' Choice papers of the August 2021 issue of the Journal of Plant Pathology, and we hope they may inspire you to pursue similar studies bound to have relevant local applications, wherever you may be.

$$
\begin{array}{r}
\text { Matteo Garbelotto, Editor in Chief } \\
\text { Luisa Rubino, Managing Editor } \\
\text { Thierry Candresse, Jaap Janse, Paolo Gonthier, Senior } \\
\text { Editors }
\end{array}
$$

Publisher's Note Springer Nature remains neutral with regard to jurisdictional claims in published maps and institutional affiliations. 